\title{
Abstracts for the International Forum on Disability Management (IFDM), London, England, September $10-12,2012$
}

\section{POST-REHA NETWORK: WORKING TOGETHER FOR DISABILITY MANAGEMENT AFTER MEDICAL CARE}

Dipl.-Psych. Gudrun Vater ${ }^{1}$, Prof Dr Mathilde Niehaus ${ }^{1}$ University of Cologne

More people with disabilities would be able to work if they received appropriate support at the right times (QECD 2010, p. 145). A complex, fragmented institutional setup, imperfect governance of service and a lack of cooperation can contribute to poor outcomes (OECD 2010, p. 163). Better coordination and cooperation is hard to achieve. To deliver the right service to the right people at the right time, a series of conditions need to be fulfilled. Potential clients should have easy access to helpful support and should face no problems in identifying the right gateway to services. The authorities should have the means to procure a broad range of services tailored to the clients' needs as much as possible (OECD 2010, p. 153). Moreover, management models, which guarantee quality-based cooperation, do not yet exist; neither between the different subsystems (horizontal networking, e.g. private service providers) nor across the border of the subsystems (vertical networking, e.g. authorities, institutions providing benefits, service providers, doctors etc.) (Toepler 2008).

The research project "POST REHA Network" (20102013) aims to develop consistent and quality-assured rehabilitation services for vocational rehabilitation. A consortium of academic partners and practitioners i.e. chemists, medical supply stores, ambulatory nursing services and providers for barrier-free buildings, work together in this project. They develop offers for the Duisburg area, which are exemplarily compiled, tested, and subsequently introduced into practice. The experiences and results are planned to serve as a "model of good practice" for further rehabilitation service networks in North Rhine-Westphalia.

In addition, this project strives to enable easy-access rehabilitation service for authorities, institutions providing benefits and customers (companies, affected employees). For comprehensive coordination a virtual pilot POST-REHA Service will be developed.

The currently existing local service network "Servicenetz Duisburg GbR" and the Association of Ambulant Nursing Care LfK, NRW e.V. assure rehabilitation service and set an example for the development of a model for a regional rehabilitation network. The University of Cologne provides advice for disability management and the Ruhr-Universität Bochum controls for quality management and evaluation ac- tivities concerning rehabilitation service and the progress of the virtual pilot POST-REHA Service.

On the one hand, the project addresses employees who suffer from stroke, spinal cord injury, amputation and heart disease. On the other hand, it deals with companies, which intend to integrate or reintegrate affected individuals and plan to implement a disability management system.

Horizontal as well as vertical networking turns out to be a challenge. First experiences and results will be presented and discussed at IFDM 2012.

\section{References}

OECD (Ed.) (2010): Sickness, Disability and Work: Breaking the Barriers. Retrieved from: http://www.oecd.org/ dataoecd/40/57/46446944.pdf

Post-Reha Netzwerk (2012): Retrieved from: http:// www.post-reha.net/index.php/home

POST-REHA Network Cologne (2012): Retrieved from: http://www.hf.uni-koeln.de/32776

Toepler, E. (2008): Qualitätsnetzwerke in der Rehabilitation. In: Prävention und Rehabilitation, Jg. 20, S. 160-167.

\section{BELGIAN EMPLOYERS' SUB-OPTIMAL KNOWLEDGE ON DISABILITY MANAGEMENT POSSIBILITIES}

K. Mortelmans ${ }^{12}$, L. Lambreghts ${ }^{1}$, G. Moens ${ }^{13}$

${ }^{1}$ Occupational Health Service IDEWE, Belgium

${ }^{2}$ Occupational Health Service Mensura, Belgium

${ }^{3}$ Katholieke Universiteit Leuven, Belgium

\section{Introduction}

In times of scarcity on labour market for specific professions, e.g. nurses and teachers, Belgian employers feel more need to invest in sick-listed employees' return to work guidance. We aimed to study Belgian employers' knowledge on current return to work legacy.

\section{Methods}

Twenty human resources managers from medium-sized companies were questioned about return to work of employees more than 4 weeks on sickness absence. A newly developed questionnaire was used, followed by a 1-hour interview.

\section{Results}

$75 \%$ of employers were unaware of having the obligation to inform the occupational health services about sick-listed employees absent from work for more than 4 weeks 
$50 \%$ had misunderstandings about the obligatory character and the timing of return to work consultations at the occupational health services.

$40 \%$ thought wrongly that occupational physicians in Belgium can - in analogy with neighbouring country the Netherlands - check the legitimacy of the employee's absence from work.

$50 \%$ did not know that employers should inform each employee more than 4 weeks absent from work about his right to consult the occupational health services to discuss or prepare work accommodations as part of a work resumption trajectory

\section{Discussion}

There may be an opportunity for the Federal Government and for Occupational Health Services to invest in clear and practical information for employers regarding disability management options.

\section{Conclusions}

The selected employers' knowledge about the Belgian legal aspects of return to work is to be improved.

\section{NETWORKING AND CO-OPERATION - A ROAD TO SUCCESS. DEVELOPING THE INTEGRATION-ORIENTED PARTICIPATION INTO WORKING LIFE}

Thomas Keck ${ }^{1}$

${ }^{1}$ Deutsche Rentenversicherung Westfalen

\section{Introduction}

Participation in working life is a central goal of medical and professional rehabilitation. Society and the social security organisms are facing great challenges in the field of the integration of older workers into the working life. New ideas of prevention and rehabilitation are required in order to promote and secure the integration capability and employability for older workers as well as for chronically ill and/or disabled persons. The Deutsche Rentenversicherung Westfalen has developed two models that are intended to guarantee a future-oriented, innovative vocational rehabilitation. The main goals are securing the earning capacity up to the retirement age, the furtherance of the employability, the direct orientation to-wards the employers by consulting visits as well as the preparation and timely provision of rehabilitation services that fit exactly.

\section{Methodology}

Model 1:

Implementation of a Company Service for Healthy Work

This new service implemented by the statutory pension insurance is a consulting and piloting service for enterprises and companies on the subjects of Industrial Health, Industrial Integration Management and Preventive Health Care in Industry. The company consultant acts as a contact on site, being at the disposal of the enterprise within the scope of consulting and support processes.

Model 2:

Integration Project RehaFuturReal

This pilot scheme is intended within the scope of the rehabilitation process to achieve and secure the workers' employability by the sustainable implementation of individualisation, flexibility and orientation towards integration. Within the scope of this pilot scheme, the die modified control of the rehabilitation process secures an active, well-structured rehabilitation management that acts from the entry throughout the consulting process and the participation provided up to the integration. The comprehensive, individual and timely consulting services will result in a permanent and exact integration into working life. The need of rehabilitation shall be determined earlier, and rehabilitation services shall be provided in a way that is oriented to each individual case, timely, and efficient.

\section{Results}

In 2011, 100 companies and enterprises received comprehensive consulting by the Company Service for Healthy Work. These were prevailingly small and medium-sized companies (up to 500 employees) from different industries. There is a huge demand of consulting and support with respect to wellstructured conceptions in the field of Industrial Integration Management (78\%) as well as to permanent and sustainable implementation of measures of Industrial Health Management $(76 \%)$. The preservation of the employability for impaired and older workers is considered to be the main goal of all efforts of the companies. (86\%)

In the integration project RehaFuturReal, the majority of participants (78\%) are recruited among the recipients of medical rehabilitation of different groups of indications (focuses: orthopaedics, cardiology). The rehabilitants' average age was 47.3 years (range of ages 33 - 57 years), that is, a rather old age for services for the participation in working life. The rehabilitants showed a high degree of motivation for attending services for the participation in working life and for the continuation of their professional activity, despite the persistence of physical impairments (83\%). Through the intensified consulting and support services as well as flanking qualification services, a professional integration prospect with their existing or a new employer, respectively, could be achieved for a great number of insured persons (65\%). As result of the quality evaluation, a skills profile could be determined for consultants during the intensified specialised rehabilitation consulting.

\section{Discussion}

Within the scope of a close co-operation of the paying organisations with the employers, the service providers and the persons entitled to the services, a co-operation network was created that enabled individualised, modularised, and flexible integration solutions. It became clear that the consultant is the pivot of the pilot scheme, his function being the information and co-operation with the companies and the comprehensive design and control of the cases. He is the pivotal contact for all of the protagonists and institutions involved. The implementation of these pilot schemes into the practice of pension insurance requires structural changes and personal contributions in particular to the intensified consulting of the persons entitled to the services and of the employers. This is a matter of adjusting the basic conditions with respect to new requirements in the field of rehabilitation and integration of people with impaired physical fitness, in order to achieve an improved and sustainable integration.

\section{Summary}

The implementation of a consulting service for companies and the development process ,,RehaFutur” explicitly requires the further development of consulting conceptions in rehabilitation. It is becoming clear that comprehensive consulting 
services and a well-targeted co-operation and networking of all persons involved will considerably improve the process of integrating handicapped persons into working life. In order to give professional rehabilitation a form that will meet the challenges of the future, the ideas worked out so far should consequently be converted into concrete measures of implementation on an interdisciplinary level.

\section{MENTAL HEALTH AND EMPLOYMENT SUSTAINABILITY IN SERVICE ORGANIZATIONS}

\section{Christine Randall ${ }^{1}$ \\ ${ }^{1}$ Griffith University, Australia}

Organizations are faced with numerous challenges related to mental health issues, absenteeism, presenteeism and staff turnover. Many organizations have realized the benefits of providing a healthy work context, but sometimes struggle to develop these ideals in practice. Despite the challenges, there are also opportunities to create environments conducive to the health of members of the organization and to the sustainability of employment relationships.

Action Research was conducted with a participant organization utilizing a systems thinking framework. Data was gathered from members of the organisation via individual interviews, focus groups and short answer surveys. Data was interpreted at each of the three phases and finally integrated to demonstrate the links between identified issues, suggested solutions and existing processes for stress and injury prevention and management.

The organization had a long history of high levels of occupational stress injuries and limited success in addressing these issues. Problems were identified with the organizational climate; job and organizational characteristics; training and knowledge about injury, illness and rehabilitation; stress management processes; and rehabilitation procedures. Organizational stakeholders suggested improvements to the organizational culture; increasing trust in the organization and between individuals; promoting ownership of prevention and rehabilitation; increasing understanding of prevention and rehabilitation processes and roles; improving relationships with external stakeholders; providing resources; revising selection processes; and streamlining prevention and rehabilitation systems. Pre-injury processes (such as selection and training of support roles, injury management awareness training and data management), hampered injury prevention and rehabilitation processes post-injury. Post-injury processes were characterized by delayed reporting of health issues; lack of clarity about roles and responsibilities; delayed focus on recovery and return to work; and lack of follow through to ensure sustainable outcomes.

The results for all three phases of the Action Research process were characterized by opposing forces seeking balance. The identified issues represented tensions between 1) the interpersonal, relational, human factors, and 2) the organizational, structural, procedural, systems components. The proposed solutions sought a balance between interpersonal and organizational needs with recurring themes around interpersonal and institutional trust and power dynamics. The existing processes for injury prevention and management indicated reciprocal influences between processes and people creating both tensions and opportunities for change. Systems thinking and bimodal perspectives, such as 'interpersonal ver- sus institutional' and 'trust versus power', highlight the complexity of addressing mental health issues, preventing injury, and achieving sustainable rehabilitation and return to work outcomes.

The findings of this action research study reinforce the need to adopt a systems approach to the development and implementation of effective disability management programs, particularly in the area of mental health. Understanding issues such as organizational trust, communication processes and power dynamics, is critical to identifying intervention points and opportunities for organizations to address mental health issues and increase the sustainability of employment relationships.

\section{AGEING WORKFORCE - IMPLICATIONS FOR EMPLOYERS}

\section{Morag Fitzsimons}

'Workers' Compensation Solutions Pty Ltd

Over the next decade, one of the major challenges for all employers across all fields of industry - whether large or small, will be to respond to the impact an ageing workforce will have on their businesses.

The risks are particularly relevant for Safety, Health and Workers' Compensation sectors where an ageing workforce is beginning to impact on absences, incidents, premiums and return to work scenarios.

In addition, employers in many industries are facing skills shortages. Forecaster Deloitte Access Economics has indicated that Australia is experiencing the sharpest fall in its working age population on record.

Despite these issues we have witnessed very little affirmative planning to address these demographic challenges - let alone the skill shortages that will surface in the next decade. Companies - particularly in the small-to-medium sectors - still appear to be operating from a reactive point of view, demonstrated apathy, complacency and a lack of urgency around these business risks.

This paper will review a programme which assists employers identify the retirement intentions or desired working trends for their mature workforce. A risk strategy is developed to assist mature workers stay longer in the workforce without increasing their risk of injuries. For those with plans to exit, this can be achieved through a coordinated approach between employer and employee to ensure knowledge capture within the employer whilst the employee has some surety around their plans and strategies for a long and healthy retirement.

The analysis of Workers Compensation data is an effective means of positioning the business case with Boards and Executive teams and will cover some of the key data sets and provide examples of interventions based on business risk.

\section{THE PERCEIVED EXPERIENCE OF SOMEONE OUT OF WORK ON SHORT TERM DISABILITY: A PHENOMENOLOGICAL STUDY}

Kristin Tugman ${ }^{1}$

${ }^{1}$ Unum (USA)

Disability incidence and the related costs and consequences are not expected to wane for any part of the globe over the next several years due to the ramifications of the aging population. Disability currently accounts for an average 
of $8-15 \%$ of an employer's payroll in the United States and these costs are expected to increase $37 \%$ over the next ten years (Hawley, Diaz, \& Ried, 2009). McVicar (2008) found that disability payments drastically increased in the United Kingdom between the 1970s and early 2000s, from 1 million to 2.7 million. Denmark has seen costs increase, and $8 \%$ of their working population is currently out of work on disability (Lund, Kivimake, Laboriola, Villadsen, \& Christensen, 2008). Sweden also complains that their costs have increased by 200 million year over year (Lydell, Grahn, Mansson, Baigi, \& Marklund, 2009). Norway indicates that disability payments are about $2.4 \%$ of their gross domestic product (Nordberg \& Roed, 2009). Australia notes that their incidence of disability has doubled between 1991 and 2003, and Canada reports that $9.9 \%$ of their working population is receiving disability benefits (Cai, Vu, \& Wilkins, 2007; Yue, 2008).

The aging worker presents significant risk for disability occurrences. Mitchell (2006) indicates that the fastest growing sector of the workforce is the 51- to 64-year-old group. Older workers between the ages of 50 and 60 years of age experience a $25 \%$ decline in physical strength as well as increased deficits in flexibility, reaction time, hearing, and stamina (Perry, 2010). Another factor that will play a role in the continued escalation of disability costs and consequences is the sandwich generation or individuals who are caring for an elderly parent and also have at least one minor-aged child (Beauregard, Obilgin, \& Bell, 2009). As the population ages, they require more daily care and research indicates that only $7 \%$ of them receive formal care (Rubin \& White-Means, 2009). This sandwiched situation creates stress on the caretaker and can decrease productivity and increase absenteeism (Neal, 2008).

When considering solutions to mitigate disability consequences, cognitive adaptation theory and cognitive appraisal have an impact on psychological adjustment and disease progression (Taylor 1983; Taylor et al., 2000; Folkman et al., 1986; Pinquart et al., 2007). Cognitive behavioural techniques have also shown some success in mitigating the length of time away from work (Brouwer et al., 2009; Watson, 2010; Tugman \& Palmer, 2004). Despite the success of cognitive techniques and the documented impact of cognitive adaptation and appraisal on adjustment, the literature does not merge these two concepts and explore how they may impact disability and return to work. As a result, this study will use a qualitative approach to understand the perceived experience of someone unable to work due to an injury or illness. The study will pay particular attention to the impact of cognitive adaptation theory and cognitive appraisal theory on return to work. The results of the study presented and suggest factors and techniques for practitioners and employers to consider in the effort to improve return to work and productivity outcomes.

\section{SOCIO-ECONOMIC SITUATION OF PERSONS WITH REDUCED EARNING CAPACITY}

\author{
Stefanie Märtin ${ }^{1}$ \& Pia Zollmann \\ ${ }^{1}$ Department of Rehabilitation Research of the German Pension \\ Insurance, Berlin.
}

\section{Introduction}

If in Germany people with reduced earning capacity cannot return to work following rehabilitation or other disability management measures they can apply for disability pension benefits. This pension is supposed to compensate for the fi- nancial consequences of invalidity allowing the persons concerned to largely maintain their standard of living. In Germany, today 1.59 million people receive such a pension. Of those, 183,000 commenced in 2010 , this equals $21.3 \%$ of all new pensions.

However, it remains unclear how good the material and social protection by disability pension benefits really is. Therefore, the German Pension Insurance initiated a research project linking routine data with a survey of people receiving such pensions with regard to their socioeconomic situation.

\section{Methodology}

Out of the insured, that started receiving disability pension benefits in 2008, in 2011 a sample of about 10,000 persons was selected randomly and asked to participate in a questionnairebased survey. The return was about $45 \%$ and representative for the target population. To determine the risk of poverty OECD's Laeken indicators were used. The household net income weighted according to need was determined using the OECD modified scale. The results were compared to the Socio-Economic Panel (SOEP), a household based survey representative for Germany.

\section{Results}

The average monthly pension was 661 Euros. For the majority this was their only source of income. Only a very small percentage received income from work or another source. However, in about $60 \%$ of the households there were other persons with income. Looking at the total household incomes, the pension in multiple person households accounted for 35\% in women and $45 \%$ in men. In single pension recipients the percentages were higher $-67 \%$ for women and $70 \%$ for men.

In addition to the income mentioned, about a fifth of the households surveyed received state aided transfer funds in order to increase the household income to the level of the "Grundsicherung", the German basic financial security. This held true for $28 \%$ of single-person households and $15 \%$ of multiple person households. The at-risk-of-poverty rate (i.e. less than $60 \%$ of the median of the net household income of the entire population, weighted according to need) was $37 \%$ in the pensioners surveyed, which is substantially higher than for the entire German population (14\%).

\section{Discussion}

The recipients of disability pension benefits themselves only rarely have other sources of income - usually due to their reduced earning capacity and lack of employment possibilities. Accordingly, they have to rely on the income of other household members or - mainly for single persons - on state aided transfer funds. Despite these possibilities the at-risk-ofpoverty rate for this group of people is very high.

\section{Conclusion}

In Germany disability pension benefits play an important role in social protection following invalidity. The level of financial protection, however, is not always sufficient. Especially for people, who cannot rely on the income of other household members, (re)integration into the workplace is necessary. To achieve this aim is a challenge for disability management.

\section{References}

DRV (2011): „Erwerbsminderungsrente: Das Netz für alle Fälle”, 6. Auflage (3/2011), S. 2, 4 

30-31

DRV Bund (2010): Rentenbestand am 31.12.2010, S. 3, DRV Bund (2010): Rentenzugänge, S. 31-32

\section{UNDERSTANDING THE TRAUMATIZED MIND AND EFFECTIVE WAYS TO TREAT AND ACCOMMODATE RETURN TO WORK}

Bruce Blythe $^{1}$

${ }^{1}$ Consultant, USA.

Psychological factors can be the most complicating issues in the practice of disability management. No doubt, physical illnesses and injuries are often accompanied by some level of psychological injury. Especially, if a "traumatic incident" creates the disabling condition, claimants have little understanding about how to manage psychological reactions. But, with swift application of psychological first aid and focused strategic intervention with trauma experts providing appropriate treatment, individuals recover and are able to return to work even when serious injury occurs.

The Traumatized Mind: When claimants are affected by assaults, robberies or witnessing traumatic incidents at work they develop traumatic stress reactions that can become impairing (mentally reliving the incident with intrusive thoughts, anxiety/depression related to the incident, and avoidance triggered by reminders of the same or similar situations). The efficacy of addressing traumatic stress reactions before they become PTSD, depression or anxiety is showing huge return-on-investment gains.

In addition to traumatic stress reactions, there are other psychologically-based barriers to recovery that are costly and often difficult for disability managers to adequately address (i.e., anger, fear, adjustment reactions, irrational beliefs, unrealistic expectations, etc.)

By understanding the traumatized mind, disability managers, employers, and treatment providers can all better influence claimants in positive directions toward recovery. This presentation will provide the "common thought patterns" that are pervasive with impaired persons. By knowing these common thought patterns, the ability to defuse these psychological barriers to recovery become increasingly attainable.

Effective Treatment and Return to Work Accommodations: According to the US National Council on Compensation Insurance, "Employees with stress-related injuries stay away from work longer than those with physical injuries." However, today, there are effective methods for early intervention of these psychological barriers to recovery without psychiatric diagnoses. With the success of early intervention programs continuing to emerge, it is prudent for disability managers to utilize these proven methods toward recovery.

The treatment model we will cover in this presentation involves a workplace psychologist working collaboratively with providers, employees and the employer to ensure the employee sees mental health providers who specialize in treating trauma and facilitating return to work with accommodations, if needed.

The treatment model includes:

- Assessment with the employee within one business day of referral
- If face-to-face services are indicated, the workplace psychologist facilitates referral to a qualified provider in the specialist network

- Strategies are implemented recognized as best practices in reducing trauma symptoms (i.e., desensitization, exposure therapy). Follow up occurs as needed, until the individual successfully returns to work

- Calls are placed to appropriate parties on the case throughout the process until the individual is able to return to work successfully

- Accommodations are employed to facilitate transition to work, if needed, in collaboration with all parties involved in the case

This presentation will provide an evidence-based case study from a very large retail company. Their return-to-work percentages following traumatic incidents increased over $90 \%$ by providing an early-intervention model. Participants will learn exactly how they did it.

\section{DOCTORS KNOW BEST - MEDICAL MODELS VS REAL LIFE}

Debbie Cohen ${ }^{1}$

${ }^{1}$ Centre for Psychosocial and Disability Research, School of Medicine, Cardiff University

The aim of the presentation is to provide the audience with an overview of the current activities in the UK to shift health professionals attitudes about work and health from one of the 'advocate' and 'providing treatment' to a more holistic and collaborative approach to the management of health and work. Many episodes of sickness absence are due to common health problems, which often relate more to psychosocial and medical issues. So demedicalising these problems and developing a more measured and proportionate response will help 'all players' health professionals, patients and employers in their management of sickness absence and rehabilitation. This presentation will describe how we have tried to address these in the UK and support attitudinal and behavioural change particularly in general practice.

1. Hussey S, Hoddinott P, Wilson P, Dowell J, Barbour R. Sickness certification system in the United Kingdom: qualitative study of views of general practitioners in Scotland. BMJ. 2004 Jan 10 328:88.

2. Money A, Hussey L, Thorley K, Turner S, Agius R. Workrelated sickness absence negotiations: GPs' qualitative perspectives. Br J Gen Pract. 2010;60(579).

3. Cohen D, Aylward M, Rollnick S. Inside the fitness for work consultation: A qualitative study. Occupational Medicine. 2009;59:347 - 52.

4. Cohen D, Khan S, Allen J, Sparrow N. Shifting attitudes: the National Education Programme for work and health. Occupational Medicine. 2012;62:371-4.

5. Cohen D, Marfell N, Webb K, Robling M, Aylward M. Managing long-term worklessness in primary care: a focus group study. Occupational Medicine. 2010; 60 (2):121-6 
THE ELECTRONIC ACTIVITY PRESCRIPTION TOOL (ARX): CHANGING THE WORK DISABILITY PARADIGM

\author{
Robin Nagel ${ }^{1}$, Steve Wiesner ${ }^{2}$, Jon Seymour ${ }^{2}$ \\ ${ }^{1}$ Consultant \\ ${ }^{2}$ Kaiser Permanente \\ ${ }^{3}$ Reed Group
}

Employers and disability administrators depend on accurate and timely information provided by physicians to manage disability programs, to comply with jurisdictional and regulatory requirements. In the best of circumstances clear and actionable activity guidance from physicians to their patients and by extension, to their employers, is critical. This optimises early, safe and suitable workplace interventions, enabling the affected employee to remain productively engaged at work.

Everyone regrets the rarity of this best-case scenario. Too often, the scarcity of clear and actionable physician guidance leads to unnecessary time away from work with subsequent delay in medical and functional recovery. Employers and insurers, when provided with unclear activity recommendations, are limited in their ability to implement safe work accommodations.

Incorporating feedback from payers, health plan patients and our medical group physicians, Kaiser Permanente (KP) embarked on a four-year project to develop the Activity Prescription (ARx) documentation tool, accessible within our electronic health record, HealthConnect. ARx allows the clinician to clearly describe and efficiently document levels of safe activity throughout the patient's healing process. An electronic interface between the $A R x$ and the Reed Group's MDGuidelines return-to-work database readily provides diagnostic-specific disability duration guidance and care management recommendations.

This presentation will illustrate the tool itself and the interdisciplinary process that led to the successful development and implementation of ARx. To optimise use of the ARx and to provide clinicians with the core concepts of disability management, a web-based training module, Work (dis)Ability Prevention and Management, was developed and will also be demonstrated.

Learning objectives:

- Understand how the ARx can efficiently support physicians in documenting accurate, patient-specific activity guidance while enhancing patient education

- Understand the roles of the key stakeholders involved in the development of the ARx

- Recognize how the electronic interface between ARx and Reed Group's MDGuidelines' disability duration database supports clinical decision-making by minimising unnecessary work disability while promoting timely medical case resolution

- Understand potential report-generating capabilities of the $\mathrm{ARx}$

The Work (dis)Ability Prevention and Management website was launched in December 2011, within KP's secure Intranet environment. Based on clinically established core knowledge, from the international literature, the content is geared toward educating KP's healthcare providers in leadingedge principles of preventing medically unnecessary work disability.
Its aim is to inform and inspire KP clinicians to affirmatively guide medical and functional recovery for their patients in terms of what activities may be safely undertaken and which should be avoided. Attention is drawn to the differentiation between the clinician's role in providing activity recommendations in distinction from the employer's role, i.e to determine safe work accommodations.

The training module also provides a video link on how to efficiently use the ARx as well as providing information on the most resourceful use of the MDGuidelines.

KP's Integrated Disability Management (IDM) programs are also featured in this website, including opportunities for active collaboration in return-to-work and safe activity advocacy for KP's employees who become injured or who suffer an illness, regardless of cause (due to a work-related injury or a personal health condition).

\section{WHAT FIRES TOGETHER, WIRES TOGETHER}

\section{Robert Aurbach ${ }^{1}$ \\ ${ }^{1}$ Deakin University, Australia}

It is well known that some people recover uneventfully, whilst others descend into disability after injury. Why does this happen?

Neuroscience has yielded new understandings of the way in which the mind adapts to stimuli and learns new behaviours. "Neuroplastic research has shown us that every sustained activity ever mapped including physical activities, sensory activities, learning, thinking and imagining' changes the brain as well as changing the mind"? (The Brain That Changes Itself, Norman Doidge, MD, James H. Silberman Books, 2007, p. 288) This research has pointed the way toward a model of 'acquired disability behaviour' that both explains and guides corrective action.

The presentation starts with an exposition of a model of how people adopt a "disabled persona", based upon neuroplasticity research. After an injury, a person experiences sensations, thoughts and fears that become the centre of their attention, particularly if they are left with time and circumstances to focus on their injury and the claims process. As the person experiences these disparate inputs linked by temporal proximity, the brain forms connections of facilitated response linking them. What wires together, fires together has become the new mantra of neuroscience. The sensations of loss of control, physical discomfort and fear about the future are commonly experienced and they link together through a facilitated neural network that causes them to be associated in the mind, as they are linked in the brain. As the claims system presents thoughts, sensations and emotions at the same time as those basic experiences, they too become wired into the facilitated neural network that replaces the injured persons pre-injury approach to the world. Over time the habit of disability is strengthened and any stimulus that activates any part of the new network of disability fires the whole. The model explains the entire range of "acquired disability behaviours" including chronic pain.

Lawyers, doctors and claims managers all contribute to the development of this unintended learned behaviour, often while completely unaware of the adverse consequences of their actions. Medicalisation of claims and defensive diagnostic testing create a focus on the injury and the belief that a magic cure will be forthcoming from the "right" doctor. Delay of 
return to work to maximise the award, strategic manipulations of the case pending adjudication and aggressive defence of the claim make the injured person model the disabled role for extended periods. Inconsistency, unresponsiveness and delay in the claims process cause economic complications and frustration for the injured. Through these and similar familiar mechanisms, our systems needlessly disable a percentage of claimants by creating exactly those habits of thought we should avoid. Lessons for professions engaged in the operation of claims systems are immediate and practical.

\section{RETURN TO WORK FOLLOWING MEDICAL REHABILITATION - RESULTS FROM ROUTINE DATA OF THE GERMAN PENSION INSURANCE}

Brueggemann $\mathrm{S}^{1}$, Zollmann $\mathrm{P}^{1}$.

${ }^{1}$ German Pension Insurance, Berlin, Germany.

\section{Background}

The German Pension Insurance (DRV), a federal authority, is one of the major rehabilitation carriers in Germany. The central objective of their rehabilitation is continued employment of the population. Patients eligible for rehabilitation usually suffer from chronic diseases and related disabilities. In 2010 the DRV carried out 996,154 medical rehabilitations. This study addresses the question to which degree over a period of two years following rehabilitation patients are gainfully employed and which factors influenced the prognosis for their return to work (RTW).

\section{Methods}

The analyses are based on process generated data of the Pension Insurance, generated annually as a longitudinal survey over a period of eight (rehabilitation/pensions) and 11 (contributions to pension insurance) years and published in spring 2012 as a Scientific Use File. The data contain information about medical and vocational rehabilitation, pensions, times of employment, unemployment and incapacity to work as well as sociodemographic data. RTW is operationalised as "employment with statutory insurance" over a period of two years following medical rehabilitation. Moderators for RTW were identified using multiple logistic regressions (SPSS 18.0), looking also at men and women separately.

\section{Results}

The following results refer to a total of 353,138 men (53\%) and 310,527 women $(47 \%)$ with an average age of 48 years having undergone medical rehabilitation in 2007 . Within 24 months following rehabilitation three quarters of the patients were gainfully employed with an average duration of 19 of the possible 24 months. More than one third was employed continually. About ten percent retired due to disability during the period analysed and four percent received old age pensions.

Multiple logistic regressions identified moderators for RTW, showing similar results to prior analyses.

RTW was influenced positively by: income of 100 Euros or more per working day in the year prior to rehabilitation application, earning capacity (last place of work) of six hours and more per day, incapacity to work lasting less than three month during the 12 months prior to rehabilitation, being employed at the time of rehabilitation application, being younger than 40 years of age as well as having a higher education entrance qualification.
A negative influence on RTW was demonstrated for: earning capacity of less than three hours per day, incapacity to work lasting over six months, no vocational education, being unemployed or not working at the time of rehabilitation application and being 60 years or older. Looking at men and women separately, basically the same influences could be shown.

\section{Discussion}

The analyses show the central importance of (un)employment prior to rehabilitation as well as of social determinants for RTW following medical rehabilitation. Health related factors are only of secondary relevance.

\section{Conclusions}

Our findings demonstrate the importance to initiate rehabilitation as early as possible, before health related disintegration from the work place occurs. Pre-existing occupational problems must be identified during medical rehabilitation and vocational rehabilitation should be initiated accordingly to allow for a goal oriented disability management.

\section{References}

Buschmann-Steinhage, R., Zollmann, P. (2008): Zur Effektivität der medizinischen Rehabilitation bei Alkoholabhängigkeit. Suchttherapie, 9: 63-69.

Deutsche Rentenversicherung Bund (2012): RehaBericht 2012 - Die medizinische und berufliche Rehabilitation der Rentenversicherung im Licht der Statistik, im Druck.

Streibelt, M., Bethge, M. (2008): Return to Work? Identifikation besonderer beruflicher Prob-lemlagen in der medizinischen Rehabilitation, Pabst Verlag.

Zollmann, P., Schliehe, F. (2003): Rehabilitation und Wiedereingliederung im demographi-schen Wandel. In: Badura, B., Schellschmidt, H., Vetter, C. (Hg.): Fehlzeitenreport 2002, Demographischer Wandel: Herausforderungen für die betriebliche Personal- und Gesund-heitspolitik, Berlin Heidelberg - New York: Springer-Verlag, 185-199.

\section{RETURN TO WORK FOLLOWING VOCATIONAL REHABILITATION}

Buschmann-Steinhage, $\mathrm{R}^{1}$, Brueggemann, $\mathrm{S}^{1}$, Zollmann, $\mathrm{P}^{1}$. ${ }^{1}$ German Pension Insurance, Berlin, Germany

\section{Background}

As one of the major rehabilitation providers in Germany in 2010 the German Pension Insurance (DRV) carried out a total of 135,211 vocational rehabilitations at a cost of 1.4 billion Euros. Vocational education is particularly time-consuming and expensive. Looking at duration and conceptual content there are three different ways of vocational education measures can be differentiated: (advanced) training (over two years, new occupation); specific qualification (one year, complementary training) and integration measures (six to nine months, repetition of basics and hands-on training). Common objective of these measures is resumption of work. This study addresses the question to which degree over a period of two years following vocational rehabilitation patients are gainfully employed and which factors influenced the prognosis for their return to work (RTW).

\section{Methods}

The analyses are based on process generated data from the "Reha-Statistik-Datenbasis" (RSD), generated annually as a 
longitudinal survey over a period of eight years. The RSD contains personal data regarding medical and vocational rehabilitation, pensions, times of employment, unemployment and incapacity to work as well as sociodemographic data with the current file covering the time from 2002 to 2009. This study looks at all rehabilitees that finished their vocational rehabilitation in 2007. RTW is operationalised as "employment with statutory insurance" over a period of two years following vocational rehabilitation. For the descriptive analyses SPSS 18.0 was used.

\section{Results}

One third of the 25,219 persons that finished their vocational rehabilitation in 2007 were women. The average age was 42.5 years. Women were on average about one year older than men. $46 \%$ were unemployed prior to vocational rehabilitation; the work ability of another $37 \%$ was in danger due to longstanding incapacity to work. These vocational problems were to a significant degree unequally distributed between the different vocational groups. After 24 months of advanced training 53\% were employed, $50 \%$ following specific qualification and only $39 \%$ following integration measures. Furthermore, age was a significant factor for RTW: of the rehabilitees under 40 years of age $52 \%$ were reintegrated into the work force, but only $39 \%$ for those aged 50+. Persons having successfully completed their vocational rehabilitation were employed almost twice as often (54\%) than those, who terminated rehabilitation or failed the final exam (28\%).

\section{Discussion}

For many vocational rehabilitees occupational disintegration is quite advanced prior to rehabilitation. Age is important for selection of the appropriate measure and for reintegration, respectively. But RTW is also influenced by the successful completion of the rehabilitation measure. In contrast to other research our study showed only minor influence by the condition of regional labour market.

\section{Conclusions}

The findings demonstrate that reintegration into the workforce can be achieved, if vocational education is customised to individual needs. Occupational problems should be identified during medical rehabilitation and vocational rehabilitation should be initiated accordingly.

\section{References:}

Deutsche Rentenversicherung Bund (2012): Reha-Bericht 2012 - Die medizinische und berufliche Rehabilitation der Rentenversicherung im Licht der Statistik, im Druck.

Erbstößer, S., Verhorst, H., Lindow, B., Klosterhuis, H. (2008): Leistungen zur Teilhabe am Arbeitsleb-en durch die Deutsche Rentenversicherung - ein Überblick. RVaktuell 11, S. 343-350

Köster, T., Fehr, M., Slesina, W. (2007): Prädiktoren der Integration in das Erwerbsleben von Teilnehmern der stationären beruflichen Rehabilitation. In: DRV-Schriften, Band 72. S. 291-294.

Slesina W., Rennert D. (2009): Prozess- und Ergebnisqualität beruflicher Rehabilitation. Regensburg: S. Roderer Verlag.

\section{LIFE DESIGN FOR PEOPLE WITH DISABILITIES}

Stefano La Porta ${ }^{1}$

${ }^{1}$ University of Cagliari, Italy.

The right to employment of people with disabilities to social inclusion is outlined in the UNO Convention (2006). The European Directive 78 (2000) on equal treatment in employment and labour does not warrant the work or its maintenance, promotion or training, of an individual who is not competent, capable and available to perform the essential functions in a specific job. Businesses or, in the case of excessively high costs of inclusion, public services must implement measures to enable disabled access to work, according to the needs of the individual and companies.

The traditional vocational guidance and career counselling should be reconsidered for people with disabilities to achieve integration for employment and social inclusion.

Social inclusion of people with disabilities is achieved by integrating family, education and employment, in the acquisition of abilities and personal capacities with the development of job skills.

Life design is a psychological support for people with disabilities and their family (Soresi 2007), into decision-making for the professional framework (Savisacks 2005) adapted to the working environment in relation to their disability (Guichard 2005).

The process of life design of people with disabilities is structured as follows:

1) Functional assessment of the person with disability ICF/OMS World Health Organization (2001).

2) Vocational guidance for people with disabilities.

3) Construction of the professional project.

4) Implement actions for disability compensation.

5) Monitoring of person and working project.

The assessment of the person with disabilities is defined by the following:

a) Personal data of the person with disabilities.

b) Functional analysis of the disability ICF/OMS 2001.

c) Educational and professional path.

d) Occupational skills and professional interests.

e) Job analysis and adaptation to the working environment.

f) The definition of the path to follow for the framework of the professional project.

Activities are identified according to three types of professional project (Benini, Pietrangeli, 2003):

1) Social work, paths for the development of social skills and interpersonal skills, with support from the school in the workplace, for people with intellectual and mental disabilities.

2) Training, development paths of professional skills and working times, through training and traineeship, for people with physical disabilities and those disabled at the first entry or re-entry job placement.

3) Professional, path to use skills in undertaking the job with the change of environment and organisation of work, to ensure the job performance of people with disability who have experience and skills. 
The task of identifying a professional project with a path allows: the increase self-efficacy (Lent, Brown, Hackett 1994), the development of professional interests (Walsh, Holland 1992) and implementation of strategies for problem solving (Heppner 1988), the acquisition of personal skills that can be used as professional competences (McIntire, Bucklan, Scott 1995), to allow the increase of the resilience of those with disabilities in the labour market (Castelli 2011).

\section{SCHOOL-TO-WORK TRANSITION OF YOUNG PEOPLE WITH DISABILITIES: THE NEED FOR HARMONISED DATA ON A NATIONAL AND INTERNATIONAL LEVEL}

Prof. Dr. Mathilde Niehaus; Lene Hodek M. Sc.; Dipl.-Soz. Dennis Klinkhammer ${ }^{1}$

${ }^{1}$ Centre for Labour and Vocational Rehabilitation, University of Cologne, Germany.

\section{Introduction}

By signing the United Nations Convention on the Rights of Persons with Disabilities in 2009, Germany recognises any form of physical, emotional, mental or sensory impairment as normal aspects in human life. Theoretically, within the framework of existing measures, people with disabilities should have the same opportunities as non-disabled, but in reality the target group still faces several problems. Difficulties in achieving equal participation in the labour market are the crucial example in this context. Therefore, it is essential to understand the school-to-work transition of young people with disabilities. Every year a large number of pupils with disabilities leave school without secondary school qualification, and even those who graduate successfully face difficulties in entering the labour market. As a result, a variety of measures to qualify the target group and to get them into vocational training programs is provided. The individual biographies of this target group are hard to verify through existing official data.

\section{Methods}

The different systems are analysed through existing official data sources on schooling, vocational rehabilitation and labour market. Data on pupils with special needs is provided by the current Conference of the Ministers of Education and Cultural Affairs of the Länder (KMK). Data on vocational rehabilitation and the labour market is mainly provided by the Federal Employment Agency of Germany (BA). A descriptive analysis of the different sources is carried out.

\section{Results}

The KMK states that most of the young people with disabilities gain no secondary school qualification (76.3\%). Only $2.2 \%$ gain a qualification beyond secondary school. This lack of qualification may lead to difficulties when young people with disabilities try to enter the labour market. Data on vocational rehabilitation seem more heterogeneous, because they depend on the BA and other service providers, for example sheltered workshops. Overall, vocational rehabilitation is offered for two different target groups: one consists of those who aim to enter the labour market for the first time and need additional qualification or benefits for their vocational education and training. The other approach focuses on reintegration after leaving the labour market or aims at transferring people from sheltered workshops to the labour market. In general, it is difficult to identify young people with disabilities within these systems.

\section{Discussion}

Difficulties in addressing young people with disabilities within these data sources result from the heterogeneous foci within the school system, the vocational rehabilitation measures and the labour market. Moreover, individual information on health and disability are treated as sensitive data. As a result, the current quality of data on disabled people is problematic and could be improved with comparative information and systematic follow-up monitoring.

\section{Conclusion}

Considering the well-differentiated systems for young people with disabilities in Germany, the challenges in statistical analyses are explicable. A better quality of data could be achieved by matching the data of the educative with the data of the rehabilitative system. Internationally recognised standards for the identification of the target group could be implemented to permit comparison by objective criteria.

\section{DISCLOSING CRIMINAL RECORDS OF FUTURE EMPLOYEES WITH DISABILITIES?}

Jun Yaeda, Rh.D. ${ }^{1}$, Takamasa Aida, M.S. ${ }^{2}$

${ }^{1}$ University of Tsukuba, JAPAN

${ }^{2}$ Tokyo Vocational Rehabilitation Center, JAPAN

\section{Introduction}

The purpose of the study was to assess employers' perceptions toward hiring individuals with disabilities having criminal records.

\section{Methodology}

A mail survey was conducted with "Special Subsidiary Companies" which promote employment of people with disabilities in Japan. Questions included:

(1) Have you ever hired criminals with disabilities?

(2) Should the criminal records be informed prior to the employment?

(3) Given a hypothetical case of an individual with intellectual disability having a criminal record, would you hire him?

(4) Generally speaking, would you hire criminals with disabilities?

(5) Are you satisfied with the criminal information management by the service providers? As of June 2011, 100 employers responded to the survey $(36 \%$ of the 276 samples).

\section{Results}

(1) Only $2 \%$ had hired criminals with disabilities in the past.

(2) The $78 \%$ of the respondents expressed that vocational rehabilitation service providers should inform such critical information.

(3) More than half respondents (58\%) said they would not hire the hypothetical case with intellectual disability having a criminal record.

(4) About $80 \%$ respondents said they would not generally hire criminals with disabilities. 
(5) The $53 \%$ of the respondents expressed dissatisfaction toward vocational rehabilitation service providers regarding their information management.

(6) More than $90 \%$ of the employers said that they feel the urgent need to discuss the issue of disclosing criminal records with the service providers.

\section{Discussion}

The results showed that most of the employers would not hire individuals with disabilities having criminal records because they did not want to put their other employees at risk should a second offence occur. The underlying ethical principle is 'non-maleficence', or 'to do no harm to others'. One of the main reasons for hiring the criminal case was the involvement of social welfare services that would provide a safety net. Other reasons included, "If he or she is eager enough to work, the criminal record does not matter", "Service providers' honesty is the key", "The individual case seemed to have repented enough", and "I would like to help him/her as a person". Ethical principles such as 'autonomy', 'justice', 'fidelity', and 'beneficence', seem to be the logic for those who would hire criminals with disabilities. If the individual is safe enough and seems to have little chance of committing a second offence, we should give him a second chance. On the other hand, other employers expressed their concerns as, "What is the merit to the company?" and "We are having enough employees with intellectual disabilities and psychiatric disabilities already". The employers also expressed that, "We do not know the effective disability management method". An information management guideline is needed for both employers and the service providers in the future.

\section{LITIGATION AND REHABILITATION}

\section{Tracey Storey ${ }^{1}$}

${ }^{1}$ Irwin Mitchell Solicitors, London, UK.

Lawyers who represent claimants in compensation claims have a duty and responsibility to consider rehabilitation at every stage of the claims process. The aim of this workshop is to look at how the claims process interfaces with NHS treatment and how the Claimant's right to opt for private treatment and care may influence discharge decisions and hopefully free up resources for other patients. Lawyers must consider how to implement early intervention, care, rehabilitation, further medical treatment, return to work, aids appliances and equipment. The role of the lawyer is to secure third party funding for this and to work with the treating team in the best interests of the patient. We will also look at the role of the Case Manager in the litigation process and the need to ensure that people with compensation claims are signposted to specialist lawyers who understand the importance of restoring people's lives after trauma

\section{WORK IS A TONIC THAT MAKES YOU WELL: REFRAMING ASSUMPTIONS REGARDING THE RELATIONSHIP BETWEEN WORK, INJURY AND DISABILITY}

\section{Nikki Brouwers ${ }^{1}$ \\ ${ }^{1}$ Interact Injury Management, Australia.}

The aim of this paper is to 'reframe' the set of conventional assumptions regarding the current international injury com- pensation system in such a way that it opens new and more effective possibilities for responding to injuries. Based on both the professional experience of the presenter/clinician and the research in the literature, it will be demonstrated that current practices for responding to injuries reinforce the injuries that they are intended to overcome. The dominant way in which this takes place will be conceptualised in terms of the notion of worklessness. It will be argued that under the current model worklessness is seen as a precondition for promoting well-being, that is, that under conditions of injury, absence from work is seen as a condition for building up strength or well-being enabling an injured person to return to work.

This research paper aims to explore the hypothesis that the more we protect the injured by precluding them from returning to work or staying at work, the more we perpetuate their identity as being ill and thus the harder it is to return to work. The research project will argue that work is itself more than a form of therapy, it is part of a person's sense of identity, an expression of themselves and their relationship to the world and thus that being at work has a central role to play in going beyond an injury mindset and restoring a sense of confidence, identity and empowerment to those who are injured.

As will be seen from the above, the research project involves two dimensions: a description of the way in which current models of international injury compensation reinforce the very issue they wish to cure and the second part involves a deconstruction of the set of assumptions around our understanding of work and worklessness. The central hypothesis of this paper is that if we reframe our assumptions around the relationship between injury and work we will open up new possibilities for not only enabling people who are injured to return to work/stay at work but see work as an opportunity for overcoming disability.

\section{RTW PROGRAM: FROM THE INVALIDITY PENSION PERSPECTIVE}

Edmund Cheong Peck Huang ${ }^{1}$

${ }^{1}$ Social Security Organisation (SOCSO), Malaysia.

The Social Security Organisation of Malaysia governs 2 schemes under the Employees' Social Security Act 1969; which are the Employment Injury and the Invalidity Pension Scheme. There are differences in managing the disabilities of the clients between the 2 schemes as the employment injury receives more traumatic musculoskeletal injury claims while the invalidity pension receives more lifestyle disease claims. Understanding the factors behind managing these cases would assist in developing a more strategic approach towards managing cases applying for the Invalidity Pension scheme.

\section{RETURN TO WORK (RTW) COORDINATION WITHIN HEALTHCARE: AN EXAMPLE FROM THE COUNTY OF ÖSTERGÖTLAND/ SWEDEN}

Dörte Bernhard ${ }^{1}$

${ }^{1}$ Linköping University, Sweden.

\section{Background}

Recent changes within Swedish welfare influence the way of working with return to work (RTW). Measures focus on a structured RTW process where traditionally different welfare actors are interacting (healthcare, social insurance, employers, occupational health, employment centres). The year 2008 
introduced a rehabilitation chain which requires coordination between the different welfare actors and has resulted into new roles and responsibilities. The healthcare system plays a key role when it comes to the RTW process. Coordinators were implemented in Swedish healthcare to support sick-listed patients in their RTW process. Internationally, rehabilitation coordinators are involved in planning and organising the RTW process and even to provide individual support to sick-listed and/or disabled persons. Several empirical attempts to classify the necessary and required skills and competencies of RTW coordinators were made in the last decade. However, research has not yet focussed thoroughly on the situation of rehabilitation coordinators in Sweden. This study explores how RTW coordinators in Sweden see their function/ mandate, investigates their practice and even focusses on their competence development.

\section{Methodology}

This study follows a phenomenological approach and focusses on the coordinators view. Because of the "young" character of the subject (phenomen) an explorative approach was chosen. This qualitative study is based on 20 semi-structured face-toface interviews with rehabilitation coordinators. The data was categorized and analysed according to the different steps of content analyses.

\section{Results}

The majority of coordinators see their mandate in relation to the healthcare centre they are affiliated to, hence workload and resources impact their performance. Their function includes mainly the administration of sick-listed patients as well as organising inter-professional meetings at healthcare. Central is their collaboration with medical doctors. Contact to other actors from the welfare system is limited. Other contacts refer to employers, yet, they are very limited. Some coordinators even provide individual support to long-term sick-listed persons. In terms of competence development their professional support systems gain in importance.

\section{Discussion}

What possibilities have coordinators in healthcare and how can they fill their mandate? Is RTW coordination the "right" place to support long-term sick-listed persons and if so, how should the healthcare system accommodate coordinators? Or, should RTW coordination be based with another welfare body? What impact can competence development of RTW coordinators have?

\section{Conclusion}

RTW coordination in healthcare is limited but could possibly be developed. A certification process outlining the coordinators competence is seen as important. Given that there is such a variety of professional backgrounds and experience, curriculum development and training ought to consider the differences and the learning habits of the coordinators.

\section{OUTCOMES OF AN INNOVATIVE JURISDICTIONAL DISABILITY MANAGEMENT STRATEGY}

\section{Wolfgang Zimmermann ${ }^{1}$ \\ ${ }^{1}$ National Institution of Disability Management and Research (NIDMAR), Canada.}

\section{Context}

In 2006, the Province of British Columbia, Canada, with a population of 4.5 million and having been selected as the host province and country for the 2010 Winter Olympics/Paralympics, embarked on a comprehensive strategy to ensure that it was a model jurisdiction for persons with disabilities by the time of the Olympics in early 2010 .

Part of this comprehensive strategy involved increasing employment rates for persons with disabilities. This involved a two-pronged strategy targeting both individuals on the social security system but also attempting to reduce the inflow of individuals into the social security system.

Government research indicated that by mid-2007, approximately 80,000 individuals with disabilities in British Columbia were receiving social assistance, which represented a net present value liability of approximately $\$ 17$ billion (unadjusted for potential increases or inflation), increasing at approximately $\$ 32$ million per month with an annual outflow rate from the system of 0.75 percent (individuals who were either retiring or dying). This was happening at the same time that British Columbia was facing a significant labour shortage due to major Olympic Games associated activity, while also experiencing a dramatic uptick in mental health claims.

The goal of the Government of British Columbia strategy was to radically lower the inflow rate into the system through collaboration with employers, which would achieve three major objectives:

(a) reduce the socio-economic impact of disabling conditions on workers and employers;

(b) increase the competitiveness of British Columbia's economy; and

(c) increase employment participation of persons with disabilities, while also addressing significant labour market challenges.

\section{Action}

The Government of British Columbia through Cabinet approval selected an internationally recognised disability management assessment tool and through a \$1 million grant offered employers the ability to assess their current disability management programming relative to internationally accepted best practice benchmarks, which would also give employers a performance improvement roadmap.

Participation in this process involved employers across all sectors of British Columbia's economy including small, medium and large enterprises as well as those in the private and public sector, ranging from purely "white collar" businesses to resource industries.

This presentation is intended to provide an overview of the

(a) societal drivers behind this strategy;

(b) the assessment strategy applied; and

(c) the evidence based socio-economic impact this approach has had on a cross-section of businesses including Vancouver Coastal Health Authority, one of six health authorities managing British Columbia's healthcare system where this strategy, over the course of two years, reduced long-term disability premiums by $\$ 2$ million, reduced short-term claim duration by 60 percent, and has resulted in long-term disability claims cost avoidance of $\$ 16.7$ million. 


\section{WHEN THE STAKEHOLDERS SPEAK: LESSONS FROM A NATIONAL ENGAGEMENT OF PERSONAL INJURY STAKEHOLDERS IN AUSTRALIA}

Robert Aurbach ${ }^{1}$

${ }^{1}$ Deakin University, Australia

In personal injury compensation schemes it is common for the various stakeholders, statutory aurthorities, and service providers offering services to the injured to be "siloed"? off from one another. Information flow, promulgation of innovative clinical approaches and coordination of care often suffer as the specialties focus on communications and educational opportunities within their ranks, at the cost of cross-specialty communications. The statutory authorities will convene stakeholders upon occasion, but usually under circumstances with familiar parties to address a set agenda. Often, little by way of new perspectives or opening of new lines of communication occurs. The same people, answering the same questions, yield little by way of new information.Deakin University saw this communications failure as an opportunity to make a unique contribution to the personal injury sector in Australia. We created a unique series of stakeholder engagement sessions in every state and territory to offer an opportunity for interested parties to meet together and voice their views, concerns and questions.

The stakeholder engagement sessions were unique in at least two respects: the method of identifying participants and the agenda for the sessions.

The method of identifying participants was based upon personal network mining. Known opinion leaders from a variety of viewpoints were identified. They were asked to recommend people who they thought might be interested in contributing to the process. Invitations were sent out and in-person interviews with those potential participants were scheduled. Those participants were introduced to the engagement series and asked to nominate a further level of participants from their personal network. The first two levels of participants were invited to the sessions, along with others that they might chose to nominate. In each instance 50 to 100 participants, representing a variety of professional specialties and stakeholders attended the sessions.

Each session was organized around a specific phase of a personal injury claim. Sessions focused on physical recovery of harm, rehabilitation, return to work and behavioural health, claims management and dispute resolution and prevention of harm. Each session was initiated with a simple question: "What constitutes success?"? with regard to that phase of the case, in that jurisdiction. Conversations were robust, with the comments recorded for later reporting and analysis.

This session will report the major findings of the cumulative national study. The commonalities amongst participants in widely varying compensation systems were significant and instructive, disclosing significant and pervasive communications failures, failures of significant feedback loops for communicating information needed by other professionals, previously undisclosed common concerns and desired systemic features and (sometimes difficult) lessons for the system managers. These findings are informative to compensation systems outside Australia, and point the way to improvements in the services provided to the injured.

\section{EMPLOY YOUNG PEOPLE WITH DISABILITIES}

Edwin L. De Vos'

${ }^{1}$ CHAMP Research and Consultancy

This presentation will look at how employers can be encouraged to regard young people with health problems or disabilities as a more attractive recruitment option in the light that growing numbers of young people enter the disability benefit systems in a number of EU-Member States. This year a synthesises report is to be published on the status of young people with health problems or disabilities, that describes policies and mechanisms designed to meet their needs and identifies good practice in Active Inclusion measures that result in employment.

\section{PREVENTING NEEDLESS DISABILITY IN ONTARIO, CANADA}

Nancy Gowan ${ }^{1}$

${ }^{1}$ Gowan Health Consultants, Canada.

For the past 5 years, Ontario has been involved in an evolution of change to bring together grassroots stakeholders to reduce needless work disability. This process has involved government, health professionals, employers, employees and payers in developing consensus based actions to help employees to stay employed while experiencing injury or illness.

\section{IT'S THE SIMPLE THINGS THAT COUNT ... TOOLS AND SERVICES FOR ENHANCING EMPLOYER ENGAGEMENT}

Lucy Macali ${ }^{1}$

${ }^{1}$ WorkFocus Australia

This session will provide a general overview of the National Disability Recruitment Coordinator service, outline its key activities to date and provide an overview of key learnings and challenges. Information will also be shared about the nature of support employers are looking for from intermediaries to drive sustainability. WorkFocus Australia will also share simple tips and tools for those working in the field to take away and apply in their work with employers.

The National Disability Recruitment Coordinator (NDRC) is a service funded by the Australian Government which aims to create more employment opportunities for people with disability nationally by supporting large employers to develop their overall level of 'disability confidence' and by filling as many of their vacancies as possible with candidates with disability.

WorkFocus Australia has managed the NDRC since March 2010 and is currently working with 31 large employers nationally on generating increased employment opportunities for candidates with disability. Large organisations that have signed partnership agreements with the NDRC cover a broad range of industries including; retail, telecommunications, postal services, contact centres, financial services and the Australian Public Service.

The NDRC essentially acts as a 'conduit' between large employers and Australian Disability Employment Services; identifying vacancies, promoting them to Disability Employment Services, assessing the quality of candidates' applications and then providing a 'short-list' service to the employer. Additionally and critically, the NDRC also provides advice to employers about the impact the candidate's disability may have upon him / her in the workplace, outlining strategies 
and any reasonable adjustments required as part of the process.

It is critical that the NDRC works closely and collaboratively with intermediaries (in this case, Australian Disability Employment Services) in order to ensure shared success and achievement of employment goals for candidates with disability. A number of different recruitment approaches have been utilised by WorkFocus Australia in order to respond to individual employer recruitment needs and to build their confidence in and capacity to welcome employees with disability into their workplaces.

A recent innovative and highly successful initiative was undertaken in partnership with WorkFocus Australia and a large national retailer, Woolworths Limited.

The overall aim of the project was to deliver a better mix of disability employment assistance and advice. A dedicated 'Disability Employment Officer' based in Woolworths was appointed through the project to focus on removing barriers to employment for jobseekers with disability through promulgating good practice and informing the development of a 'how to' guide for company use.

For WorkFocus, the opportunity to work more closely with one of Australia's largest employers provided a tremendous opportunity to gain an 'insider's view' of the highly dynamic retail environment. Awareness and understanding of large employers' needs was deepened and an opportunity to refine current approaches in addressing them identified.

For Woolworths, the project lifted the profile of disability further internally and enhanced an already very positive and productive commitment to providing some of Australia's most disadvantaged jobseekers with an opportunity to make their contribution to the workforce.

The innovative nature of this project was recognised formally in May 2012 by the Australian Human Resources Institute, which selected Woolworths as a finalist in its inaugural Diversity Awards program.

In summary;

- This project secured its projected goal of 45 placements over a 12 month period

- There was a $375 \%$ increase in placement outcomes between 2010/11 and 2011/12 for people with disability employed in the project region

\section{RETURN-TO-WORK AND DISABILITY MANAGEMENT - APPLYING THE UN DISABILITY CONVENTION}

Anne Hawker ${ }^{1}$

${ }^{1}$ Ministry of Social Development, New Zealand

The United Nations Convention on the Rights of People with disabilities (UNCRPD) came into force on the 3 May 2008. This was significant document because it was the first international treaty of the $21^{\text {st }}$ century and the first to involve civil society.

One of the most significant changes embodied in the UNCRPD was viewing people with disabilities as subjects with rights. This moves focus away from seeing disability as an impairment to be fixed to eliminating the barriers created by society that prevents persons with disabilities from enjoying their human rights on an equal basis with others. Such barriers include, for example, negative atti- tudes, discriminatory policies and practices, and inaccessible environments.

One of the important fundamental changes embodied in the UNCRPD is the notion of inclusion. Inclusion is not about inserting persons with disabilities into existing structures, but about transforming systems to be inclusive of everyone.

Given the importance of UNCRPD for those states that have ratified the Convention, this paper will explore how disability management can be used as a tool in the achievement the employment outcomes embodied in Article 27 Work and Employment. The presentation will also examine the impact of the UNCRPD on Disability management practice.

Other important tools that impact both the disability community and world of work are the World Report on Disability; Community based rehabilitation and the International Classification of Health and Function. Viewed together they have created a substantially changed environment in which Disability management now operates. This paper will explore those changes and their impact.

\section{ASSESSMENT FOR JOB ANALYSIS}

\section{Stefano La Porta ${ }^{1}$}

${ }^{1}$ University of Cagliari, Italy.

European Directive 78 (2000) on equal treatment in employment and labour does not warrant the work or its maintenance, promotion or training, of an individual who is not competent, capable and available to perform the essential functions of a specific job. The directive requires companies or, in the case of excessively high costs of inclusion, public services the burden of implementing actions to enable disabled access to work, according to the needs of individuals and companies in real situations.

Job placement services are defined by International Labour Organisation in the "Management of disability in the workplace" (OIL 2003). Placements go through the following phases: selection, recruitment, training and career development.

For the realisation of projects of integration, public services must carry out job analysis with the overcoming of disability in the workplace.

Job placement services provide firms with advice on how to manage the integration of people with disabilities, working in production environments according to business needs. The environmental and organisational adaptation of the workplace ensures the quality and quantity of the job function of people with disability (Riessner, Shrey, Zimmermann 1997).

The advice provided contains the following activities: inclusion of people with disabilities in the proper workplace (Lepri, Montobbio 1994), job analysis and job skills (Spencer and Spencer 1995) to find the technical and organizational solutions to carry out job responsibilities of people with disabilities (McIntire, Bucklan, Scott 1995).

It is necessary, for the construction of the path of integration, the use of tools of job analysis in order to take into consideration the following elements:

1) The assessment of people with disabilities to a bio-psychosocial ICF/WHO. This assessment points out physical or mental impairment, according to the type of disability 
involved, to the activities that the person can perform and the response received by the external environment. The analysis allows you to be aware of the limitations and opportunities of the disabled person.

2) The analysis of work resources and professional interests of the person, based on personal history and professional training, highlighting personal interests that have led to the work activities. This is done according to SDS tests (Holland 2005), which analyses labour resources in accordance with the workplace.

3) The planning and implementation of integration projects with the use of a multi-disciplinary actions according to the KSAOS model (McIntire, Bucklan, Scott 1995) through rehabilitation and educational support in the conduct of business activities and training removal of architectural barriers and adaptation of tools.

Our research has developed an assessment tool for the job analysis for disability manager in public services.

\section{IS 'ANY JOB' A GOOD JOB IN A RECESSION?}

\section{Stephen Bevan ${ }^{1}$ \\ ${ }^{1}$ Centre for Workforce Effectiveness, The Work Foundation, Lancaster, UK.}

Gordon Brown once argued that the UK should aim for both full and fulfilling employment. Implicit in this aspiration is the notion that just 'having a job' should not be sufficient for most people and that employment in the 21 st century UK labour market should be a source, among other things, of wellbeing, personal growth and meaning for as many as possible. The recession and a sharp increase in unemployment may well have put this aspiration on 'hold' for a while, but the weight of evidence to support the view that job quality, employee health, engagement and productivity are closely linked is now becoming substantial and should not be forgotten in the UK as the labour market makes its gradual recovery in the coming years.

But should people be expected to accept 'bad' jobs, even in the teeth of a recession? How do we convince more employers of the case for 'good jobs'? Research has identified a number of barriers to the growth of 'good jobs'. Overcoming these barriers is essential if we are to give more access to good jobs from which both they and the wider economy will benefit in the years to come. This presentation will highlight the importance of doing better on this agenda.

\section{TENDENCY OF CLIENT'S PARTICIPATING IN A RTW PROGRAM IN A DEVELOPING COUNTRY}

\section{Roshaimi Mat Rosely ${ }^{1}$ \\ ${ }^{1}$ Social Security Organisation (SOCSO), Malaysia}

Most often in developing countries, RTW programs are not associated with injuries or diseases while participation in such programs is crucial in assisting injured workers to be integrated back into society. A research was conducted to study the tendency of workers insured under the Employees' Social Security Act 1969 (Malaysia) to participate in a Return to Work Program provided by the Social Security Organisation of Malaysia. Such information is expected to assist the or- ganisation in implementing initial intervention strategies to increase a client's participation in a RTW program.

\section{THE ATTITUDE OF PAKISTANI SOCIETY TOWARDS THE PERSONS WITH HIV (AIDS)}

Professor Dr Shahida Sajjad ${ }^{1}$

${ }^{1}$ University of Karachi, Pakistan

In 1981, physicians described a syndrome involving a deficiency of the immune system. In 1986, the virus was given its current name of Human Immunodeficiency Virus (HIV). By that time, the disease was well known as Acquired Immune Deficiency Syndrome (AIDS). The first case of AIDS in a Pakistani citizen was reported in 1987 in Lahore, one of the major cities of Pakistan. During the late 1980s and 1990s, it became evident that an increasing number of Pakistanis, mostly men, were becoming infected with HIV while living or traveling abroad. Upon their return to Pakistan from abroad, some of these men subsequently infected their wives who, in some cases, passed along the infection to their children. (National HIV/AIDS strategic framework 2001 - 2006, Pakistan).

The present survey was conducted to find out the attitude of Pakistani society towards people with HIV (AIDS). The objectives were to create awareness in Pakistani society about HIV (AIDS), to investigate the services provided to person with HIV (AIDS) by rehabilitation centres in Karachi, to explore if Pakistani Society has the knowledge about the causes and preventions of HIV (AIDS), and to find out the attitude of society as perceived by person's with HIV (AIDS) towards them.

The sample consisted of 10 doctors working in the field of HIV (AIDS), 10 patients suffering from HIV (AIDS) and 50 differently aged groups of people, all selected through a purposive sampling method from Karachi, the biggest city of Pakistan. The data was collected with the help of three structured questionnaires. The questionnaire for the doctors who were approached through different hospitals and rehabilitation centres in Karachi investigated their opinion about the services provided to persons with HIV (AIDS). The questionnaire for general public of different aged group explored their awareness of HIV (AIDS), and their attitude towards people with HIV (AIDS). The questionnaire for the patients with HIV (AIDS) investigated the attitude of society towards them, and the services provided to them by the rehabilitation centres in Karachi.

The results indicate that in Pakistani society, there is a lack of awareness about HIV (AIDS), medical facilities available in terms of screening, prevention, and diagnosis as well as outpatient treatments, and counselling is very limited and costly. People in our society have a sympathetic attitude towards the person with HIV (AIDS) and they have the opinion that HIV (AIDS) spreads through sexual contact.

The study recommends that persons with HIV/AIDS and their families need moral, psychological, financial and medical support from society and the Government. There is a need to increase the availability and accessibility of special AIDS care clinics for HIV positive persons with well-equipped and wellversed health care providers who should be specially trained to take care of such patients. (Khan, S.A. 2006) 


\section{ACCESS TO MULTIDISCIPLINARY REHABILITATION: SCREENING BASED DECISION MAKING AS AN ALTERNATIVE TO CASE-MANAGEMENT}

\section{Marco Streibelt ${ }^{1}$ \\ ${ }^{1}$ German Federal Pension Insurance (GFPI), Department of Rehabilitation, Germany}

Work-related interventions have become an integral part of multidisciplinary rehabilitation (MR) programmes offered by the German Federal Pension Insurance (GFPI). Studies showed concordantly the effectiveness of work-related MR focusing on patients with extensive work-related problems. Therefore, the identification of such problems has to be an integral part of effective access management. With a step model of an access management system (Step AMS) an alternative to case management is presented which tries to balance between centralised decisions and the needs of the individual. Approval of claims for MR normally is based on information delivered by the claimant like diagnosis (ICD10) or information on severity of illness and health insurance (e.g. insurance contributions). Step AMS additionally includes criteria to classify the claimants into homogeneous groups concerning extensive work-related problems for an optimal steering into specialised rehabilitation centres. SIMBO-C, a screening instrument for the identification of extensive work-related problems was tested regarding usefulness in this context.

\section{NEW JOB ADJUSTED DISABILITY RATING METHOD IN KOREA}

Jong UK Won ${ }^{1}$

${ }^{1}$ Department of Occupational and Environmental Medicine, Yonsei University Medical College, South Korea.

\section{INTRODUCTION}

The criteria or definition of the physical impairment differs from country to country or from generation to generation. There are many methods or criteria for measuring the degree of disability in Korea. McBride disability evaluation method has also been used to evaluate the degree of disability for automobile accident compensation or damages suit. However, these disability rating methods don't reflect the current Korean society and medical developments. Finally Korean Academy of Medical Society (KAMS) developed the new impairment rating guidelines. The purpose of this study was to develop the disability rating scale according to their job using the KAMS guideline.

\section{METHODS}

The state of California has developed the schedule for rating permanent disabilities in workers' compensation. They applied the vocational factors to impairment rate. They calculated the Future Earing Capacities (FEC) according to the type of disability which was applied to the impairment rate to switch the impairment rate to disability rate. They also grouped all jobs to apply the vocational factors to the disability rate.

We benchmarked the California permanent disability rating guideline. We grouped all jobs in Korea the same way as they did in California. KAMS impairment guideline was used for the impairment rating. All jobs are categorised with their physical activities and professional skills based on the job dictionaries in Korea. We modified the occupational variants table to apply to Korean jobs and KAMS impairment rate. However, the FEC could not be calculated because there was no personal data for disability and their future earnings. So, we modified the occupational adjustment table for the occupational variation.

The differences were plotted to compare between whole body impairment rate and job adjusted disability rate. KAMS job adjusted disability rates were compared to the McBride disability rates and workers' compensation rates in Korea.

\section{RESULTS}

1,206 occupations were grouped in to the 43 occupational groups. The types of disabilities were categorised in to 50 disability groups and 43 occupational groups. The occupational disability indexes have the digit from 1 to 7 . The number 1 means the disability is not related to the job or it does not affect the performance on the job. The number 7 means the disability is the most important to perform the job.

The differences of McBride disability rates inconsistently varied from $0 \%$ to $35 \%$ while the differences of KAMS disability rates varied consistently from $0 \%$ to $18 \%$. The differences between whole body impairment rates and KAMS disability rates were the largest at around $50 \%$ of impairment rates and the smallest at around $1 \%$ or $100 \%$ of impairment rate. The KAMS disability rates were slightly higher than McBride disability rates for upper extremities but lower for lower extremities and internal organs.

\section{CONCLUSIONS}

This is the first Korean job adjusted disability rating method. This has been under the field experiment by the Supreme Court. It has some weak points but its impairment rating is more scientific and it reflects current Korean society. It should be further updated and modified.

\section{PEOPLE FIRST - STAY AT WORK, RETURN TO WORK RE-DESIGN. LESSONS LEARNED IN A BC PILOT PROJECT AT VANCOUVER COASTAL HEALTH (VCH)}

Anne Harvey ${ }^{1}$

${ }^{1}$ Vancouver Coastal Health, British Columbia, Canada

This presentation highlights how an innovative approach to disability management is driving the creation of a healthy healthcare workplace that includes workers with health challenges. Beginning in February 2009 Vancouver Coastal Health $(\mathrm{VCH})$ negotiated Letters of Understanding with our 3 major union partners to move disability management services in house from a third party provider. Early results were very encouraging with projected cost savings of $\$ 17.6$ million over 10 years and the lowest incidence of new LTD claims for nurses in the province. Unintended consequences were a $300 \%$ increase in the volume of work, poor quality data, significant customer service complaints from unions, managers and staff, focus on early intervention to the detriment of other issues (Worksafe (WCB), Long Term Disability, Duty to Accommodate) and lack of collaboration between Disability Management staff and their counterparts in Labour Relations. VCH applied a project management approach to these issues and focused on supporting injured and/or ill workers to return or stay at work through a number of interventions including; transitional work, modified work, accommodation into own or other job. This work engaged a multi-disciplinary 
team including support from LEAN transformation services to achieve optimal outcomes while maintaining productivity gains. This project produced significant changes in how the work was tracked, defined and allocated resulting in improved outcomes while continuing to maintain and enhance gains, both human and financial, of decreasing the incidence of needless work disability.

\section{SUPPORTED EMPLOYMENT FOR PEOPLE WITH SEVERE AND ENDURING MENTAL HEALTH PROBLEMS}

Jed Boardman'1
${ }^{1}$ South London and Maudsley NHS Foundation Trust, UK.

This talk will review the evidence for the effectiveness of supported employment schemes for people with psychoses, particularly Individual Placement and Support (IPS) schemes. The implications of these schemes for mental health services will be discussed.

\section{MANAGING MENTAL HEALTH AT WORK AND PREVENTING LONG TERM DISABILITY. A 3 STAGE MODEL FOR ORGANISATIONS LARGE AND SMALL}

Bob Grove ${ }^{1}$

${ }^{1}$ Centre for Mental Health, UK.

Bob Grove will briefly review the evidence on preventing mental ill health at work, early identification/intervention and rehabilitation for those who do not recover as expected. He will propose a 3 stage (stepped) model, consisting of relatively simple, low-cost measures which address these issues and can be applied by employers large and small.

The costs of common mental health problems to employers are very high and include a large element of lost production due to individuals experiencing increasing difficulties and distress which go unrecognised and for which no help is offered (sometimes called presenteeism). Often employees in this situation go on to long term absence, thus compounding the problems and increasing the costs. At every point in the journey either to long term absence and disability or to recovery, the quality of relationships in the workplace and outside is critical. It is in employers' and employees' interests to learn how to recognise unmanageable levels of distress and to keep relationships supportive and optimistic of full recovery and return to work. Even on the rare occasions this is not possible, well trained managers and good organisational policies and culture can minimise difficulties and the need to resort to expensive legal hearings.

\section{EMPLOYERS AND EMPLOYEES WORKING TOGETHER WHEN SOMETHING GOES WRONG: A PROGRAM FOR EMPLOYEES ON LTD WITH MENTAL ILLNESS}

\section{Melanie Weller ${ }^{1}$ \\ ${ }^{1}$ Consultant, Ontario, Canada.}

This presentation will examine a unique Canadian based program which supports employees who are on long term disability due to mental health conditions to become engaged in the community.

Bell launched an unprecedented, multi-year charitable program to support mental health across Canada in September 2010 . Practically addressing a pressing national health concern, mental illness, Bell's five-year, $\$ 50$ million initiative sup- ports an extensive range of programs to enhance mental health in every aspect of Canadian life.

One of the unique programs launched in May 2011 included the company funded provision of occupational therapy support for employees on long term disability to find community based or company based volunteer opportunities. The purpose of the program is to establish and maintain support for employees with mental illness in the community through volunteer initiatives.

This pilot program allows employees with mental health conditions that may not have the ability to perform profitable and productive work, to be engaged in a community based activity on a voluntary basis. This program allows an employee with a mental illness to maintain quality of life and social engagement in the community. Being involved in this type of program allows the employee to contribute in the community and maintain social connections which will support their overall health and wellbeing.

Gowan Consulting worked with Bell Canada to develop a model for the program, program objectives and terms of reference. Over the past year Gowan Consulting has provided occupational therapy intervention for approximately 50 employees. This presentation will outline the pilot program model, objectives, criteria for involvement, feedback, challenges and results.

The facts of mental illness and its impact on Canadians are startling:

At least one in five Canadians experiences a form of mental illness at some point in their lives' every one of us has a family member, friend or colleague who will experience mental illness

Mental health funding is modest relative to other health care issues' mental illness represents $15 \%$ of Canada's health care burden but receives only $5 \%$ of health care funding

Just one-third of Canadians who need mental health services actually receive them.

Mental illness is the number one cause of workplace disability in Canada's accounting for 30\% of disability claims and $70 \%$ of disability costs

Mental illness costs the Canadian economy $\$ 51$ billion each year in lost productivity every day, 500,000 Canadians are absent from work due to a form of mental illness.

\section{WORKPLACE DISABILITY MANAGEMENT FOR WORKERS WITH MUSCULOSKELETAL OR MENTAL DISORDERS: A COMPREHENSIVE NARRATIVE REVIEW}

Marie-José Durand ${ }^{1}$, Marc Corbière, Marie-France Coutu, Daniel Reinharz, Valérie Albert, Quan Nha Hong

${ }^{1}$ Université de Sherbrooke, Quebec, Canada

\section{Introduction}

Musculoskeletal and mental disorders are among the two most important causes of work absenteeism. Several studies on the effectiveness of interventions aiming to facilitate the returnto-work of workers with these disorders have been developed. To date, most studies have focused either on a particular disorder, without having an integrated perspective. While musculoskeletal and mental disorders are considered to be two distinct entities, overall, the best practices on workplace disability management might be similar. The aim of this study was to identify the common principles on the disability 
management of workers with musculoskeletal disorders or mental disorders.

\section{Methodology}

A narrative review of the literature on workplace disability management was undertaken. The scientific literature was searched using several databases (CINAHL, MEDLINE, PsycInfo, Scopus and ABI/INFORM complete). The search was limited to systematic reviews on workplace disability management of workers with musculoskeletal or mental disorders and published between 2000 and 2011. Also, the grey literature (i.e. unpublished documents and research reports) was searched using websites of research centres involved in work disability. Finally, the list of documents found was send to the co-investigators of this study and they were asked to complement the list.

\section{Results}

A total of 8 systematic reviews, 9 guidelines, 8 book chapters and 4 research reports were retained in this study. The analysis of these documents identified a number of organisational strategies and actions as well as several stakeholders involved in the return-to-work process. Based on the literature synthesis, a general workplace disability management conceptualization was elaborated. This conceptualization contained 6 main steps: (1) Off work and recovery period, (2) First contact with the worker, (3) Assessment of the worker and his/her work, (4) Development of a return-to-work plan including accommodations, (5) Work re-entry, and (6) Monitoring of the return-to-work process. For each step of this conceptualization, specific organisational strategies and actions were identified. Also, the roles and responsibilities of stakeholders involved in this process were depicted.

\section{Discussion}

The analysis of the documents retained in this study brings to light several common points on the workplace disability management of musculoskeletal and mental disorders. Only some points, such as stigmatization, may differ between disorders and request specific intervention. Analysis of the documents retained revealed that having clear organisational policies on health and disability management is important. These policies must advocate a supportive approach for workers and include disability management practice based on active strategies put in place by various stakeholders.

\section{Conclusion}

This review shed light on organisational strategies and actions that should be taken to improve disability management and facilitate return to work. They are presented into an integrated conceptualization that could be applicable to persons with work disability due to musculoskeletal or mental disorders. Future research should study the implementation of this conceptualization and its effectiveness and cost-effectiveness in different contexts.

\section{EVALUATING CHANGES ASSOCIATED WITH A STEPPED CARE EARLY INTERVENTION MODEL FOR INCOME PROTECTION CLAIMANTS WITH MENTAL HEALTH CONDITIONS; AN OPEN FOLLOW-UP STUDY}

Stephanie McCahon ${ }^{1}$

${ }^{1}$ Swiss Re, UK.

\section{Introduction}

The incidence of income protection (IP) claims for workplace absence as a result of mental health conditions is increasing. There are limited studies demonstrating specific return to work outcomes for people with mental health problems in an insurance setting.

We developed a stepped intervention model based on the evidence-based principles outlined by Waddell, Burton, \& Kendall (2008). The service was developed to assist IP customers with mild to moderate mental health problems to stay in work and return to work.

The aim was to encourage the development of rehabilitation within the insurance industry, through an evidence-based and cost-effective service to assist people with mental health conditions to stay in or return to work.

The purpose was to fund intervention before a claim had been made - to get people back to work faster and subsequently prevent long-term disability and the consequent insurance claims.

\section{Methodology}

The mental health stepped-care model was developed in collaboration with a rehabilitation provider with experience using a similar intervention model for musculoskeletal conditions. The model involved initial telephone triage (with a mental health clinician), education, bibliotherapy, guided self-help, and signposting to other appropriate services. Following triage, the service 'streams' were stepped by the level of intervention intensity which could be: coaching with an occupational psychologist, telephone case management, or face-to-face input if required.

An open study commenced with a UK-based IP insurer in November 2010. The study population included new claimants with mild to moderate mental health conditions. Upon lodging an IP claim, study participants were referred to the provider for telephonic triage and allocation to an appropriate intervention 'stream'.

Pre-trial data was collected, which included a Patient Health Questionnaire (PHQ-9) and Generalized Anxiety Disorder (GAD-7) scores. Outcome measures included; repeat of PHQ and GAD, a customer 'satisfaction questionnaire', costs of intervention, and return to work outcome.

\section{Results}

Analysis of 80 cases indicated a reduction in costs for intervention and length of claim duration when compared with the average intervention costs and average length of claim duration for traditional claims management practices. Improvements were noted between pre and post intervention including: 59\% improvement in scores on the PHQ-9 and a $66 \%$ improvement in scores on the GAD-7 scale. Customer satisfaction for the service was $92 \%$.

We continue to collect more cases, so this is an interim analysis. 


\section{Conclusion}

An evidence-based model of stepped intervention is associated with improved health outcomes for people with mental health conditions. A randomised controlled trial is the necessary next step to test the effectiveness of this intervention, but would be challenging to implement in this industry context.

In income protection the provision of rehabilitation is generally outside policy terms and conditions and is traditionally completed at 6 or 12 months after absence. Increasing the evidence base for a stepped early intervention approach will enable us to analyse the benefits of this model for insurers, claimants and employers and in doing so challenge the traditional insurance approach to management of mental health claims.

\section{COGNITIVE AND BEHAVIOURAL THERAPIES FOR FUNCTIONAL AND LONG-TERM HEALTH CONDITIONS}

Peter White ${ }^{1}$

${ }^{1}$ Barts and the London Medical School, London, UK.

This workshop will review the efficacy of behavioural interventions in various functional somatic syndromes and long term health conditions. We will then review the factors that mediate and moderate efficacy, and determine the essential ingredients of successful therapy. By the end of the workshop, attendees will know present understanding of what works, why they work, and for whom they work.

Key references: White PD et al. Comparison of adaptive pacing therapy, cognitive behaviour therapy, graded exercise therapy, and specialist medical care for chronic fatigue syndrome (PACE): a randomised trial. The Lancet 2011;377:823-36. McCrone P et al. Adaptive pacing, cognitive behaviour therapy, graded exercise, and specialist medical care for chronic fatigue syndrome: A cost-effectiveness analysis. PLoS ONE 2012 7(7): e40808.

\section{APPLYING CBT IN THE TREATMENT FOR CHRONIC PAIN: EMPOWERING INDIVIDUALS FOR IMPROVED PAIN MANAGEMENT AND INCREASED FUNCTION INCLUDING RETURN TO WORK}

\section{Kate Harri ${ }^{1}$ \\ ${ }^{1}$ Behavioural Medical Interventions, Minnesota, USA.}

This workshop will feature a unique and emerging treatment modality utilized in the management of chronic pain patients in the United States - the use of Cognitive Behavioural Therapy (CBT) for short-term, solution-focused recovery from injuries. Outcomes of this treatment modality will be shared including average length of treatment and return to work statistics. Case examples will be provided to illustrate the process.

Chronic pain presents a challenge for patients, treatment providers, nurse case managers, and insurance carriers. $\mathrm{Pa}-$ tients experiencing unremitting pain are faced with a threat to their well-being including reduced ability to conduct daily activities and the development of anxiety and depression. Medical providers can be frustrated by a lack of progress in treatment and frequently prescribe pain medications that patients can become dependent on or result in significant side effects. Often providers are reluctant to authorize psychological treatment, with the concern that the treatment will not be effective or that the patient will not attend sessions with a mental health provider because they are being "accused" of the pain being "all in their head". However, the psychosocial stressors in an injured person's life are often a major contributing factor in delaying recovery from injuries.

Cognitive Behavioural Therapy (CBT) has been shown to be effective in treatment of depression, anxiety and chronic pain. It is a very robust process between patient and mental health clinician; addressing the "behaviour" of the patient, with homework assignments to work on between sessions to help the individual practice skills to lead a more functional life. CBT does not invalidate a patient's pain ... rather it embraces a patient where they are at and provides coaching for a more functional life, both with instilling a positive attitude and resulting in a more active life.

The workshop will describe in detail the partnership between a major health care employer in the US and BMI on this cutting edge service delivery, starting with identifying injured workers' at high risk for prolonged chronic pain via a pain screen questionnaire. The second step then involves contacting all parties involved in the patient's care to discuss adding CBT to the treatment plan. It is critical that the injured worker and attending physician understand and agree to the CBT approach before it is initiated. An initial assessment session and up to nine face-to-face sessions with a CBT therapist constitute the treatment parameters. Care oversight is provided by a workplace psychologist to ensure the patient attends sessions, and the focus of CBT provided by the mental health clinician remains on coaching strategies to reduce pain and increase function. A coordinated and timely RTW plan is put in place via case management, that involves collaboration with all stakeholders including the injured worker, treating physician, CBT therapist, nurse case manager, workplace psychologist, insurance carrier and employer representative.

\section{THE PSYCHOSOCIAL FLAGS FRAMEWORK AND WORK-RELEVANT MUSCULOSKELETAL PROBLEMS}

\section{Kim Burton ${ }^{1}$ and Nick Kendall}

${ }^{1}$ University of Huddersfield, UK.

Work should no longer be seen as toxic; it is in fact generally good for our health and wellbeing. Safety at work is a crucial consideration, but attempts to prevent common musculoskeletal problems at work have been a failure: arguably that's probably because we've been chasing the wrong goal. The very nature of musculoskeletal problems is that, like all common injury and health problems, they are ubiquitous in the general population. Furthermore, they interfere with the ability to work - the problem can readily be work-relevant irrespective of the cause.

Modern concepts of rehabilitation for common health problems acknowledge that work is good and prolonged absence is detrimental. The focus is firmly on encouraging activity and participation, which is embodied in facilitating early return to work (RTW) or helping people to stay at work (SAW), and seeing work as part of the rehabilitation process. The approach is based on the biopsychosocial model, which recognises that biological, psychological and social factors all play a part in the expression of pain and disability.

The accumulating evidence has led to a reconceptualisation of how best we should manage musculoskeletal problems at work: the question is not so much what has happened; rather how can we facilitate participation in the face of workrelevant symptoms (irrespective of their source). The answer 
is about overcoming the biopsychosocial obstacles that act as impediments to staying at work or returning early.

What is termed the Psychosocial Flags Framework has been devised to help understand and identify psychosocial obstacles. People usually need help to overcome or navigate around obstacles. This is where Flags come in - they point to the obstacles in need of action. The process is: identify - plan - action.

The obstacles can be identified by looking for the Flags - signals that things will get in the way. It's about looking for unhelpful behaviours and circumstances. Anything about the person, the workplace or the context (including influential others) that stands in the way of early return to work. Sam's story flags up a sequence of common obstacles. Helping Sam requires a plan of action. Developing a plan is about agreeing goals and sorting out who does what when. Taking action is all about overcoming obstacles: the action must address the identified flags and obstacles, using both healthcare and workplace interventions. Psychosocial factors, such as beliefs, fears, and avoidance behaviours need to be tackled. Psychosocial interventions such as problemsolving training and suitable coping strategies can usefully supplement exercises and information/advice, and contribute to increasing activity. Clinical intervention should take a stepped care approach - providing just what's needed when it's needed, and should involve the workplace. Importantly, an accommodating workplace can be the key. Relatively simple temporary modifications to the job or the way it is scheduled can impact on the success and sustainability of SAW and early RTW outcomes. Modified work, if needed, should always be offered as a transitional arrangement for getting back to usual work.

\section{THE PROGNOSTIC VALUE OF FUNCTIONAL CAPACITY EVALUATION (FCE) IN OCCUPATIONAL REHABILITATION}

Volker G. Grosser ${ }^{1}$

${ }^{1}$ BG Trauma Centre, Hamburg, Germany.

\section{Introduction}

Functional Capacity Evaluation (FCE) has become increasingly firmly established as a tool at the interface of medical and vocational rehabilitation. The system developed in the USA in the 1980s by Susan Isernhagen is a comprehensive kinesiophysical test of a person's ability to perform work-related tasks. This method relies on the specially trained therapist's expertise to determine maximum function by observing standardized functional criteria, i.e. prime movers (muscles), accessory muscles, body mechanics, speed, heart rate and other physical factors; subjective factors, such as pain reported by the patients and their observed pain behaviours, are recorded, but are not applied as primary evaluation criteria. This study addresses the prognostic value of FCE in occupational rehabilitation.

\section{Methodology}

145 patients with work-related injuries (1/3 upper extremity, $1 / 3$ lower extremity, $10 \%$ spinal and pelvic, $10 \%$ neurological, 15\% combination injuries) had undergone FCE at the Trauma Hospital Hamburg (BUKH) in 2008/2009. The main indication for FCE was prolonged rehabilitation with failure to return to work. The median time from accident to FCE was 411 days. In 124 (102 men, average age 42 years, SD
11.7; 22 women, average age 46 years, SD 10.9) cases (86\%) follow-up data about the results of vocational rehabilitation could be obtained in co-operation with the appropriate regional workmen's compensation insurers using a standardized questionnaire.

\section{Results}

Based on the results of the FCE a return to the work originally carried out at the time of the accident was recommended in $82(66 \%)$ of the 124 cases with follow-up data, in 52 of these 82 cases workplace adjustments were recommended. 52 of these 82 cases (63\%) actually returned to their original work, 11 to another work, 19 did not return to work. 9 who did not return to work had been unemployed at the time of the FCE. In 32 cases it was deemed that the functional deficits permanently precluded a competitive return to the original work necessitating an occupational re-orientation. 3 of these returned to their original work nevertheless, 12 to another work, 15 did not return to work, 1 was on sickleave, in 1 case data were not available. In 10 cases a definitive statement could not be made at the time of FCE, mainly because treatment options had not been fully utilized yet. 3 of these eventually returned to their original work, 2 to another work, 3 did not return to work, in 2 cases data were not available.

\section{Discussion}

The study population consisted mainly of patients with workrelated injuries in whom rehabilitation was prolonged with failure to return to work. Considering this pre-selection the overall prognostic value of FCE was good. Apart from the assessment itself FCE also helped to ameliorate avoidance behaviour on the part of some patients thereby promoting return to work. A subgroup of patients benefited from previously not utilized treatment options that were identified in the course of FCE.

\section{Conclusion}

FCE is a useful tool to guide occupational rehabilitation and predict its outcome. The actual success of occupational rehabilitation, however, is also influenced by psychosocial factors such as availability of employment and motivation.

\section{RETURN TO WORK3}

\section{K. Mortelmans ${ }^{12}$, M. Verjans ${ }^{1}$}

${ }^{1}$ Occupational Health Service IDEWE, Belgium

2 Occupational Health Service Mensura, Belgium

\section{Introduction}

In Canada and the Netherlands, RCT's proved that the Sherbrooke model is an effective and cost-saving method to induce sustainable work resumption for patients off work over 1 month due to back problems. The model offered an individually tailored, on the workplace based, step-by-step multidisciplinary return to work strategy. We aimed to adapt the Sherbrooke model to the Belgian social security system and labour market needs.

\section{Methodology}

We organised discussion groups with sickness absence experts and human resource managers. The European Social Fund supported financially. 


\section{Results}

- To enhance chances of sustainable use of the model, even after study cessation, easily implementable tools were developed based on company needs. E.g. we responded on company's requirements to enlarge focus from the sicklisted worker and developed a tool making co-workers coresponsible for the worker's successful work resumption trajectory.

- To address the complicated situation of 3 physician groups (general practitioners, social insurance physicians and occupational physicians), all involved in disability management, we invested in interventions on mutual knowledge, information exchange and cooperation tools.

- Belgian employers have limited financial incentives for return to work management. We therefore included companies having difficulties finding suitable personnel due to the labour market scarcity. Participating companies committed to fulfil $85 \%$ of multidisciplinary work resumption advices and to report in detail and structured on non-followed advices.

- Disability statistics and recent research evidence underline that psychiatric-psychosocial reasons for prolonged sickness absence are nearly as important as musculoskeletal problems, and that non-medical factors prolonging sickness absences are frequently present. We decided to include patients irrespectively of their pathology.

\section{Discussion}

The 'Return-to-Work3' project implements the adapted model in 2012 in 5 companies, employing together over 8000 employees. The Occupational Health Service IDEWE will provide multidisciplinary return to work advices for 100-200 cases.

\section{Conclusion}

We will present preliminary results.

\section{THE IMPORTANCE OF PATIENT EMPOWERMENT}

\section{Mary Cowern ${ }^{1}$ \\ ${ }^{1}$ Arthritis Care (UK)}

Arthritis and musculoskeletal conditions are one of the principle causes of disability and one of the most frequently reported chronic conditions affecting all age groups. One in five people in the UK live with some form of arthritis. Arthritis is a lifelong debilitating condition and for some it can take their life away. It's chronic, often invisible and can lead to depression and isolation. Arthritis can reduce employment opportunities, limit income and for many, restrict social and leisure activities. People are often left to cope with the pain and impact of arthritis alone due to the misconception that there is nothing that can be done.

Living with arthritis is exhausting and challenging. You have to make sense of a bewildering array of treatments and options, make adjustments to your life and cope with other people's reactions to your condition. It is vital therefore that people with arthritis are given the help and support to understand and take ownership of their condition. However this doesn't come easy.

Mary's short introductory presentation to the workshop illustrates from a personal perspective the challenges of taking control again and the difference empowerment can make in transforming recovery and regaining independence.

\section{SERVICE APPLICATION: STROKE MANAGEMENT}

\section{Tom Balchin ${ }^{1}$}

${ }^{1}$ Action for Rehabilitation from Neurological Injury (UK)

At present only a fifth of patients' rehabilitative needs are met 12 months after stroke. The UK Stroke Strategy highlights the importance of community programmes guided by the voluntary sector and the National Institute for Health Research indicates the need for rehabilitation which is onestep removed from therapy. ARNI is the only UK charity which trains and matches specialist exercise instructors with stroke survivors who require further functional training and monitoring after formal therapy interventions stop.

ARNI has refined an approach to stroke recovery over 10 years, incorporating evidence from stroke reviews that suggest intensive task-related practice and resistance training allied to the personalising of physical coping techniques can lead to functional improvements. From 2008, many UK stroke networks, associations, councils, charities and centres have sponsored exercise instructors through the ARNI FTS 300 hour practical and theory Accreditation incorporating this approach. In return, instructors give commitment to teach individuals intensively one-to-one in patients' homes, and run group classes. An extensive illustrated manual (The Successful Stroke Survivor) has been made available for the general market so that any stroke survivor can tap into the Approach and seek to do better by practicing at home and community gyms as appropriate.

87 instructors have been accredited and are working with stroke survivors of all ages who have mild to moderate levels of disability. Successes are being reported; e.g. in Chaul End Centre, Luton, 12 months of training took place from July 2010 to July 2011 using 4 ARNI instructors in one-hour, weekly sessions. Participants $(n=24)$, reported improved mobility, range of movement, action control, confidence and reduced fear of the consequences of exercise. Service audit data reported 24 ambulance call-outs for fallers during the year preceding intervention. In the year of the intervention there were no call outs, with an ambulance service saving of $£ 7,200$. Further savings of $£, 5,482$ were due to reduction in care packages (patients could transfer themselves or with one carer, instead of two), reduction in nursing input, catheter care, respite care, appliance support and medications.

There exists a subset of stroke survivors who need the support of trained exercise instructors to guide functional recovery after formal therapy finishes. The ARNI Approach has achieved many anecdotally-reported successes. Particularly successful is an innovative rotational strategy to teach patients to reach a standing position from the floor without requiring the use of a support or another person. A Brunel University feasibility study into the efficacy of ARNI Approach ran from August 2010 to December 2011 in collaboration with Hillingdon Hospital. This revealed successes in many areas from better balance and gait control to enhanced confidence and coping ability. A full clinical effectiveness trial is planned by the National Institute of Health Research's Collaboration for Leadership in Applied Health Research and Care for the South West. Pilot studies are underway: 
in December 2011 funding in order to implement a proposal, entitled 'IGO' (I Get Off the floor), was achieved.

\section{THE IMPACT OF PSYCHOSOCIAL FACTORS ON CLAIMS OUTCOMES IN THE GROUP INCOME PROTECTION MARKET: A PROSPECTIVE PILOT STUDY}

Monica Garcia ${ }^{1}$

${ }^{1}$ Swiss Re (UK)

\section{Introduction}

Work absenteeism in the UK due to ill health has been documented as a significant financial burden for employers and society.

This research explores the impact of psychosocial factors on return to work after illness or injury. The sample was individuals on sick leave making an insurance claim through a group income protection scheme. We hypothesized that psychosocial factors would predict not returning to work.

\section{Methodology}

Participants were 120 employees, working for a UK bank who were absent from work due to illness. Follow up (T1) was 6 months after the baseline data collection stage (T0).

Psychosocial variables were chosen after conducting a literature review, and these were: social support, self-efficacy, fear avoidance, work related beliefs, coping, social embarrassment, anxiety and depression. Questionnaires were all standarised and validated from previous work. The internal validity and reliability of the measures were confirmed in a pilot study of 65 individuals. All variables were categorical. Baseline questionnaires were completed after 19 weeks of absence (T0). The following outcomes were measured a) Return to work (RTW), b) no RTW, c) redundancy/resignation. For the purpose of this study outcomes b, and c, were grouped together.

Data collection started in August-2011 and will continue until December-2012. A 6 month follow up of the last set of participants is expected for June-2013, with results to be reported in September-2013.

The sample by June-2012 consisted of 25 participants. Due to the sample size, preliminary association analyses were conducted utilizing the Fisher's exact test.

\section{Results}

Most participants were females $(80 \%)$. The mean age was 41.44 year $(\mathrm{SD}=2.40)$. Two significant associations to the RTW outcome were found. Individuals who did not return to work were less likely to believe they would return to work at baseline ( $\mathrm{p}$-value $=0.006$ ), and they were more likely to have reported higher levels of depression at baseline ( $\mathrm{p}$-value $=$ 0.006). There were no significant associations found for any of the other variables, although some trends were identified.

\section{Discussion}

The preliminary results suggested that the expectation that not returning to work was more likely in those who were depressed and did not expect to return to work at baseline.

Limitations include the small number of participants to date, which limited the power analysis. It is therefore likely that some of the findings are due to chance. However, the results of this pilot study and the tool developed could be utilised to test statistical power, and form the basis of a larger research study.

\section{Conclusion}

In spite of the limitations described, the findings appeared to support the role of certain psychosocial variables on return to work after illness. The role of beliefs and depression has previously been documented as potential predictors of long term sickness absence in the non-insured population. If these results are confirmed with the collection of more data, this work will support early intervention of claims targeted at beliefs or mood or both.

\section{THE EXPERIENCES AND PERCEPTIONS OF WORKPLACE RTW COORDINATORS: AN AUSTRALIAN PERSPECTIVE ON THE ROLE AND CURRENT TRAINING.}

\section{Joanna Bohatko-Naismith}

${ }^{1} \mathrm{PhD}$ (Candidate), Australia

Two decades ago the role of the Return to Work (RTW) Coordinator was introduced to the Australian workplace and they are now critical in the facilitation of workplace RTW. RTW Coordinators are required to manage the successful transition of the injured worker to their pre-injury position, develop and implement RTW programs, accommodate the injured worker with suitable duties, and provide clear guidance on the workers' compensation process. There is little research on the skills required to effectively perform this role, or whether current training is meeting the needs of the RTW Coordinator.

\section{INTELLECTUAL DISABILITY AND SOCIAL WORK}

Stefano La Porta ${ }^{1}$

${ }^{1}$ University of Cagliari, Italy.

\section{Introduction}

In light with new experiences of social inclusion for people with intellectual and learning disabilities, thinking about the Paralympics and other projects for the integration of work, we describe a method of development of social working skills with a multidisciplinary approach.

Occupational therapy is based on maintaining and developing skills and abilities of people for autonomy in daily life through execution of simple or complex tasks, increasing creativity and problem-solving.

Sports for disabled people consist in performing a physical activity, through training and practice of a sport with rules, in a social context with human relationships, in order to achieve social integration.

Social working is based on the performance of work tasks with a social role based on rules and responsibilities, in order to acquire job skills and working integration.

\section{Methodology}

The implementation of an educational process (Wygosky 1936) for the development of skills and personal autonomy (Soresi 2007) through execution of work tasks becomes easier with a social role (Montobbio 1993) and with the design of a project for social inclusion (Ianes 2003). There are three phases:

1. Evaluation of intellectual disability through ICF / WHO and functional capacity;

2. Personal portfolio of activities: family, school, sports and social; 
3. The construction of a project of social and labour integration for the development of a social role.

Project of social working should consider the following aspects:

a Find a suitable working environment, with organisations willingness to accommodate the person;

b Identification of a simple work task, with qualitative and quantitative aspects;

c Determine performance with support activities for the person with disabilities.

The goal of project is to develop work skills in people with intellectual and learning disabilities.

\section{Results}

24 projects for people with intellectual disabilities, aged between 16 and 35 years, were run and gave the following results: 9 cases of change of social role, 7 cases of non-acceptance of the social integration project work, 8 cases of failure to acquire job skills and a work role.

\section{Discussion}

During the duration of the project the following issues were highlighted:

- Requirements of people with intellectual and learning disabilities with specific levels of autonomy

- It is necessary to develop social working projects without integration: health and family, school and social

- Importance of the evaluation of people with disabilities and activities they perform in a context

- Role of businesses in projects of social working into process of education

- Duration of the projects, in our view a period of not less than 3 years

- Coordination and implementation of social projects working with integration of school activities, sports and social.

\section{Conclusion}

People with intellectual and learning disabilities can achieve social inclusion through sport and work, however this requires a process of projects at social working. 